\title{
EFEKTIVITAS FORMAT PENDOKUMENTASIAN KEPERAWATAN
}

\author{
TASYA NIA NUDDIN HALAWA \\ tasyahalawa1705@gmail.com
}

\section{Latar Belakang}

Dokumentasi keperawatan adalah setiap catatan baik tertulis maupun elektronik yang menggambarkan layanan keperawatan yang diberikan kepada klien dan dapat digunakan sebagai bukti bagi tenaga yang berwenang. Dokumentasi keperawatan yang berlaku di rumah sakit saat ini umumnya dilakukan secara tertulis (paper based documentation). Pendokumentasian merupakan bukti legal pelaksanaan pelayanan di rumah sakit. Kualitas pelayanan disuatu rumah sakit salah satunya dapat dilihat dari pelaksanaan pendokumentasian asuhan keperawatan..Pendokumentasian berguna bagi rumah sakit dalam meningkatkan standar akreditasi, sebagai alat komunikasi antar profesi, indikator pelayanan mutu, bukti tanggung jawab, dan tanggung gugat. Kelengkapan pendokumentasian asuhan keperawatan merupakan bagian dari kualitas pelayanan keperawatan di rumah sakit. Pelaksanaan pendokumentasian adalah indikator kinerja perawat yang dipengaruhi oleh karakteristik dan beban kerja perawat.

kelengkapan pendokumentasian adalah pelatihan dan beban kerja. Ada hubungan antara masa kerja, pelatihan dan beban kerja dengan kelengkapan pendokumentasian. Direkomendasikan untuk pelatihan pendokumentasian bagi perawat dan meninjau ulang jumlah perawat serta penempatan tenaga sesuai dengan beban kerja di ruangan. Pelayanan dan asuhan keperawatan terhadap pasien merupakan bentuk pelayanan profesional yang bertujuan untuk membantu pasien memulihkan dan meningkatkan kemampuan dirinya tindakan perawat dilakukan secara komprehensif dan berkesinambungan. Dengan adanya undang-undang perlindungan konsumen (UUPK) rumah sakit dituntut lebih meningkatkan pelayanan.Pelayanan keperawatan dilaksanakan dengan suatu sistem atau pola kerja yang disebut dengan sistem penugasan. Sistem penugasan terdiri atas penugasan mandiri, fungsional, tim, modular dan primer. Sistem penugasan keperawatan tidak hanya menekan-kan proses tetapi juga hasil. 
Kata kunci: dokumentasi keperawatan, karakteristik perawat, kelengkapan pendokumentasian

\section{Metode}

Untuk mengukur pelaksanaan pendokumentasian asuhan keperawatan dengan membandingkan antara perawat yang beban kerjanya berat dan perawat yang beban kerjanya ringan analisa bivariat untuk mengalisa hubungan pengetahuan, beban kerja dan pemanfaatan teknologi informasi dengan kualitas dan kelengkapan dokumentasi keperawatan serta analisis multivariat untuk menganalisa faktor dominan yang berhubungan dengan kualitas dan kelengkapan dokumentasi keperawatan. Metode ini mempunyai kelemahana yaitu memerlukan waktu yang cukup lama untuk mengisi form yang tersedia,membutuhkam biaya percetakan form yang cukup mahal, sering hilang atau terselip, memerlukan tempat penyimpanan yang luas dan menyulitkan pencarian kembali saat diperlukan. Disamping itu masih banyak perawat yang tidak tahu data apa yang harus dimasukkan dan bagaimana dokumentasi keperawatan yang benar, untuk itu perlu adanya inovasi pencatatan dengan menggunakan pencatatan berbasis elektronik.

\section{Hasil}

Pelaksanaan atau tindakan adalah pengelolaan dan perwujudan dari rencana yang telah disusun pada tahap perencanaan. Pada tahap pelaksanaan ini dokumentasi menjadi sangat penting karena merupakan pernyataan dari kegiatan atau aktivitas yang otentik dari perawat. Dokumentasi tentang pasien memberi bukti tindakan mandiri dan kolaboratif yang dilakukan perawat, respon pasien terhadap tindakan keperawatan dan perubahan-perubahan yangterjadi. Penentuan prioritas dilakukan karena tidak semua masalah dapat diatasi secara bersamaaan. Oleh karena itu hirarki Maslow tentang kebutuhan dasar rnanusia merupakan pedoman dalam rnenentukan prioritas dengan memperperhatikan keluhan utama pasien. Selain itu juga masih terlihat penulisan rencana tindakan keperawatan yang tidak teratur dan kurang mengacu pada diagnosa keperawatan yang telah ditetapkan. Di dalam perencanaan juga perlu diperhatikan pcrumusan tujuan yang hendak dicapai dari intervensi yang telah diberikan. Dengan adanya tujuan ini akan mempermudah perawat di dalam melakukan evaluasi. Adanya perolehan skore yang masih kurang 
dari standar tersebut menyebabkan perawat mengalami kesulitan di dalam melakukan evaluasi. Keterlibatan pasien dan keluarga juga harus diikutsertakan di dalam penetapan rencana keperawatan. Karena antara perawat, pasien dan keluarga harus bekerjasama di dalam intervensi agar dapat mencapai tujuan dengan baik Pelaksanaan atau tindakan adalah pengelolaan dan perwujudan dari rencana yang telah disusun pada tahap perencanaan. Pada tahap pelaksanaan ini dokumentasi menjadi sangat penting karena merupakan pernyataan dari kegiatan atau aktivitas yang otentik dari perawat. Dokumentasi tentang pasien memberi bukti tindakan mandiri dan kolaboratif yang dilakukan perawat, respon pasien terhadap tindakan keperawatan dan perubahan-perubahan yang terjadi

perawat merasakan kemudahan saat mengisi dokumentasi keperawatan dengan menggunakan SIMPRO, dan perawat menginginkan SIMPRO dilaksanakan di ruang perawatan.

Dalam memecahkan rangkaian masalah diatas digunakanlah metode perubahan menurut Lewin. Model perubahan Kurt Lewin menawarkan pendekatan terstruktur yang dapat membantu perawat mengidentifikasi kebutuhan akan perubahan, menavigasi melalui proses perubahan, dan mencapai tujuan atau hasil yang diinginkan.Pendekatan Lewin untuk manajemen perubahan sangat bermanfaat bagi keperawatan. Pendekatan ini juga dapat membantu perawat dalam menganalisis proses perubahan dan dalam mengidentifikasi kekuatan yang mendukung atau menolak perubahan Lewin mengidentifikasi kekuatan ini sebagai kekuatan pendorong dan kekuatan penahanan kekuatan pendorong memulai perubahan dan membantu organisasi mencapai tujuan yang mereka inginkan.

Kekuatan penahan, di sisi lain, adalah kekuatan statis yang melawan kekuatan pendorong dan mencegah terjadinya perubahan.Bila kekuatan pendorong dan kekuatan penahan setara, keadaan ekuilibrium tercapai. Agar perubahan terjadi, keadaan ekuilibrium ini harus terganggu $\mathrm{Hal}$ ini terjadi ketika kekuatan pendorong lebih kuat daripada gaya menahan, atau sebaliknya, ketika kekuatan penahan lebih lemah terlibat dalam aktivitas yang mendorong perubahan ke depan dan justru menyebabkan perubahan terjadi kekuatan pendorong yang berkaitan dengan penerapan dokumentasi elektronik meliputi keinginan untuk memperbaiki metode dokumentasi, kepercayaan bahwa dokumentasi elektronik akan memfasilitasi akses terhadap informasi klinis yang akurat dan komprehensif, pengalaman sebelumnya 
dengan komputer, dan sikap positif terhadap komputerisasi. Kekuatan pendorong potensial lainnya meliputi pelatihan yang memadai, manajemen yang mendukung, keinginan untuk memperluas pengetahuan pribadi, sumber keuangan yang memadai, dan budaya organisasi yang positif. Oleh karena itu kekuatan pendorong harus di kuatkan, dengan melakukan brainstorming untuk meminta masukan terhadap pelaksanaan SIMPRO ini, dan melakukan pelatihan ulang untuk pemakaian SIMPRO. Self efficacy perawat penting dalam penggunaan SIMPRO karena dapat menentukan keberhasilan penggunaan, meningkatkan kualitas dokumentasi keperawatan dan kualitas pelayanan keperawatan kekuatan pendorong harus di kuatkan, dengan melakukan brainstorming untuk meminta masukan terhadap pelaksanaan SIMPRO ini, dan melakukan pelatihan ulang untuk pemakaian SIMPRO.

\section{Pembahasan}

Salah satu bagian dari ilmu kesehatan ialah ilmu keperawatan. Ilmu keperawatan berkembang seiring kemajuan ilmu pengetahuan dan teknologi dan sesuai dengan perkembangan jaman. Keperawatan sebagai profesi merupakan salah satu pekerjaan dimana dalam menentukan tindakan didasari pada ilmu pengetahuan serta memiliki kertampilan yang jelas dalam keahliannya, selain itu sebagai profesi keperawatan mempunyai otonomi dalam kewenangan dan tanggung jawab dalam tindakan serta adanya kode etik dalam bekerjanya kemudian juga berorientasi pada pelayanan dengan melalui pemberian asuhan keperawatan kepada individu, kelompok atau masyarakat Dokumentasi keperawatan terdiri dari keterampilan berkomunikasi untuk pengumpulan data dan menciptakan hubungan baik antara perawat dan klien dalam pemecahan masalah klien. dokumentasi proses keperawatan yang merupakan metode pemecahan masalah secara sistimatis sesuai kaidah keperawatan dan standar dokumentasi dapat memberi informasi pernyataan kualitas dan kuantitas dokumentasi untuk memperkuat pola pendokumentasian keperawatan.

Pendokumentasian asuhan keperawatan yang tidak lengkap mengakibatkan mutu Rumah Sakit akan menurun pendokumentasian yang baik mempunyai ciri-ciri berdasarkan fakta, data yang akurat, kelengkapan, ringkas, terorganisasi, ketepatan waktu, mudah untuk dibaca. Dokumentasi asuhan keperawatan yang berkualitas harus terdapat unsur keakuratan, kelengkapan, dan kerelevananan. Kegiatan 
dokumentasi keperawatan yang tidak lengkap dalam pendokumentasian, keakuratan dan tidak relevan maka akan terjadi kesulitan dalam melakukan pembuktian tindakan yang sudah dilaksanakan dengan baik dan benar Pendokumentasian merupakan unsur pokok dalam tugas dan tanggung jawab hukum setelah melakukan tindakan keperawatan kepada pasien perencanaan yang terdiri dari (penegakan diagnosis keperawatan, penentuan target sasaran, dan perencanaan keperawatan), pelaksanaan, dan yang terakhir evaluasi atau penilaian yang berkelanjutan.

Pelaksanaan dokumentasi keperawatan merupakan salah satu alat ukur untuk mengetahui, memantau, dan menilai suatu pelayanan asuhan keperawatan yang dilakukan oleh rumah sakit. Dokumentasi keperawatan tidak hanya mencerminkan kualitas perawatan saja tetapi membuktikan pertanggunggugatan setiap tim keperawatan. Oleh karena itu, jika kegiatan keperawatan tidak didokumentasikan dengan baik, akurat, obyektif, dan lengkap serta sesuai dengan standar asuhan keperawatan maka sulit untuk membuktikan bahwa tindakan keperawatan telah dilakukan dengan benar Keberhasilan pendokumentasian asuhan keperawatan sangat dipengaruhi oleh seorang perawat sebagai ujung tombak dalam memberikan asuhan keperawatan bahwa faktor individu yang memengaruhi perilaku kerja antara lain umur, lama kerja, pendidikan, dan pelatihan. Produktivitas seorang pekerja menurun dengan bertambahnya umur, sedangkan lama kerja mempunyai hubungan yang positif terhadap produktivitas pekerjaan Proses pelaksanaan dokumentasi asuhan keperawatan dapat dinilai berdasarkan standar yang diterapkandi rumah sakit .Standar dokumentasi adalah suatu pernyataan tentang kualitas dan kuantitas dokumentasi yang dipertimbangkan dengan baik dalam suatu situasi tertentu. Standar dokumentasi memberikan informasi adanya suatu ukuran terhadap kualitas dokumentasi keperawatan Perawat memerlukan suatu standar dokumentasi untuk memperkuat pola pendokumentasian dan sebagai petunjuk atau pedoman praktik pendokumentasian dalam memberikan asuhan keperawatan.

Perkembangan pengetahuan dan teknologi membuat orang berpikir lebih kritis, termasuk dalam penggunaan layanan kesehatan, oleh karena itu perawat sebagai salah satu petugas kesehatan diwajibkan untuk melakukan dokumentasi yang baik tentang asuhan keperawatan agar ketika ada masalah yang muncul antara pasien dan perawat, dokumentasi dapat digunakan sebagai bukti otentik yang dapat melindungi perawat dan pasien. Menulis dokumentasi yang akurat dan lengkap 
memudahkan perawat untuk mengidentifikasi masalah sehingga mereka dapat memberikan intervensi yang sesuai dengan masalah yang dihadapi oleh pasien dan secara tidak langsung akan meningkatkan mutu layanan perawatan. Menurut Depkes RI, salah satu indikator mutu dokumentasi asuhan keperawatan dapat dilihat dari kelengkapan dokumentasi keperawatan yang dilakukan oleh perawat. Menulis dokumentasi keperawatan yang tidak lengkap dan tidak akurat dapat mengurangi mutu layanan keperawatan.

Menulis dokumentasi keperawatan yang tidak sesuai dengan standar akan menyebabkan kesalahan diagnosis dan pelaksanaan tindakan yang tidak tepat. Ketidak lengkapan dokumen dan ketidakpatuhan dengan standar yang ditentukan akan membuat sulit untuk membuktikan bahwa tindakan keperawatan telah dilakukan dengan benar dokumentasi asuhan keperawatan di sebagian besar fasilitas kesehatan, terutama rumah sakit, belum ditulis secara lengkap Hal ini disebabkan oleh beberapa faktor seperti rendahnya pemahaman perawat tentang penulisan dokumentasi dan pekerjaan pencatatan asuhan keperawatan dirasa cukup memberatkan Perawat juga merasa bahwa menulis dokumentasi membutuhkan banyak energi, waktu dan pikiran; intervensi langsung kepada pasien lebih penting daripada dokumentasi Perawat beralasan tidak menyadari pentingnya dokumentasi standar karena perawat lebih banyak melakukan kegiatan di luar tanggung jawab perawat (kerja koordinasi dan pendelegasian wewenang) sehingga menambah beban kerja perawat, sistem dokumentasi yang sulit dan membutuhkan banyak waktu, dan tidak semua kemampuan dan pengetahuan perawat adalah sama dalam menulis dokumentasi sesuai dengan standar.

Dokumentasi keperawatan merupakan suatu yang mutlak harus ada untuk perkembangan keperawatan khususnya proses profesionalisasi keperawatan serta mempertahankan keperawatan sebagai suatu profesi yang luhur dan terpandang di masyarakat. Dokumentasi keperawatan dalam bentuk dokumen asuhan keperawatan merupakan salah satu alat pembuktian atas tindakan perawat selama menjalankan tugas pelayanan keperawatan. Penelitian ini dilakukan dengan cara mengambil seluruh sampel status pasien atau rekam medis pasien yang dirawat pada bulan Januari 2009, dengan jumlah sampel seluruhnya adalah 90 berkas, dengan syarat pasien bukan rawatan ulangan di bulan yang sama. Hasil analisa data pendokumentasian pada tahap pengkajian mendapatkan skor 56,11\% (kategori 
cukup), pendokumentasian pada tahap diagnosa keperawatan mendapatkan skor $36,67 \%$ (kategori kurang), pendokumentasian pada tahap perencanaan keperawatan mendapatkan skor $17,11 \%$ (kategori kurang), pendokumentasian pada tahap tindakan keperawatan mendapatkan skor 57,78\% (kategori cukup), pendokumentasian pada tahap evaluasi keperawatan mendapatkan skor 52,78\% (kategori kurang), dan pendokumentasian pada tahap catatan asuhan keperawatan mendapatkan skor 92,22\% (kategori sangat baik).

Sehingga diharapkan kepada pihak Rumah Sakit untuk dapat meningkatkan mutu dokumentasi keperawatan dengan upaya mengadakan pelatihan yang berkaitan dengan pendokumentasian asuhan keperawatan. Dokumentasi merupakan bagian dari administrasi sebagai jaminan pelayanan yang diberikan kepada pasien dan dapat mendukung kualitas pelayanan yang diberikan Dokumentasi dibutuhkan untuk keamanan pasien dan menjaga catatannya untuk tetap jelas, akurat, dan komprehensif menjadi bermanfaat bagi perawat dalam pekerjaan sehari-hari Dokumentasi keperawatan merupakan bukti pencatatan dan pelaporan yang dimiliki perawat dalam melakukan catatan perawatan yang berguna untuk kepentingan klien, perawat, dan tim kesehatan dalam memberikan pelayanan kesehatan dengan dasar komunikasi yang akurat dan lengkap secara tertulis dengan tanggung jawab perawat .Dokumentasi ini penting karena pelayanan keperawatan yang diberikan pada klien membutuhkan catatan dan pelaporan yang dapat digunakan sebagai tanggung jawab dan tanggung gugat dari berbagai kemungkinan masalah yang dialami klien baik masalah kepuasan maupun ketidakpuasan terhadap pelayanan.

\section{Penutupan}

kebijakan terkait pelayanan keperawatan yang bermutu dengan meningkatkan kelengkapan dokumentasi keperawatan melalui bidang keperawatan dengan melengkapi format dokumentasi keperawatan dan aturan yang sama untuk setiap ruangan dan memberikan kesempatan pada perawat untuk mengikutsertakan atau mengadakan pelatihan terkait dokumentasi keperawatan dengan sistem komputerisasi Dokumentasi keperawatan yang berlaku di rumah sakit saat ini umumnya dilakukan secara tertulis (paper based documentation). Metode ini mempunyai kelemahan yaitu memerlukan waktu yang cukup lama untuk mengisi form yang tersedia, membutuhkam biaya percetakan form yang cukup mahal, sering hilang atau terselip, memerlukan tempat penyimpanan yang luas dan menyulitkan 
pencarian kembali saat diperlukan. Diperlukan inovasi dokumentasi keperawatan dengan menggunakan dokumentasi berbasis elektronik. Dokumentasi keperawatan berbasis elektronik ini memberikan keuntungan bagi perawat dalam hal waktu pendokumentasian yang lebih singkat, keterbacaan data dan kemudahan akses bila dibandingkan dokumentasi dalam format kertas.

Dokumentasi keperawatan merupakan suatu yang mutlak harus ada untuk perkembangan keperawatan khususnya proses profesionalisasi keperawatan serta mempertahankan keperawatan sebagai suatu profesi yang luhur dan terpandang di masyarakat. Dokumentasi keperawatan dalam bentuk dokumen asuhan keperawatan merupakan salah satu alat pembuktian atas tindakan perawat selama menjalankan tugas pelayanan keperawatan.

\section{Daftar Pustaka}

1. Simamora, R. (2009). Dokumentasi Proses Keperawatan

2. Simamora, R. H., Purba, J. M., Bukit, E. K., \&Nurbaiti, N. (2019). PenguatanPeranPerawatDalamPelaksanaanAsuhanKeperawatanMelaluiPelat inanLayanan Prima. JPPM (JurnalPengabdian Dan PemberdayaanMasyarakat), 3(1), 25-31.

3. Wulandari Dyah Fitri \& Hanny Handiyani.2019. PENGEMBANGAN DOKUMENTASI KEPERAWATAN BERBASIS ELEKTRONIK DI RS X KOTA DEPOK DENGAN MENGGUNAKAN TEORI PERUBAHAN LEWINS. Jurnal Keperawatan Global Volume 4 No 1

4. Rosmalia, Dewi , Rizanda Machmud dkk.2014. Analisis Sistim Manajemen Dokumentasi Keperawatan pada Poliklinik Gigi Rumah Sakit di Bukittinggi. Jurnal Kesehatan Andalas Volume 3 No 1

5. Noorkasiani, Gustina \& R. Siti Maryam.2015. FAKTOR-FAKTOR YANG BERHUBUNGAN DENGAN KELENGKAPAN DOKUMENTASI KEPERAWATAN. Jurnal Keperawatan Indonesia, Volume 18 No.1 
6. Josua Edison Mangole \& Sefty Rompas A. Yudi Ismanto.2015. HUBUNGAN PERILAKU PERAWAT DENGAN PENDOKUMENTASIAN ASUHAN KEPERAWATAN DI CARDIOVASKULAR AND BRAIN CENTER RSUP PROF. DR. R. D. KANDOU MANADO. E-journal Keperawatan (e-Kp) Volume 3 Nomor 2

7. Muryani, Endang Pertiwiwati, Herry Setiawan.2019. KUALITAS PENDOKUMENTASIAN ASUHAN KEPERAWATAN DI RUANG RAWAT INAP (Studi di RSUD Kalimantan Tengah).Nerspedia,Volume 2 No 1

8. Noorkasiani, Gustina, R. Siti Maryam.2015. FAKTOR-FAKTOR YANG BERHUBUNGAN DENGAN KELENGKAPAN DOKUMENTASI KEPERAWATAN. Jurnal Keperawatan Indonesia, Volume 18 No.1

9. Candra Saputra, Yulastri Arif, Fitra Yeni.2019. FAKTOR YANG BERHUBUNGAN DENGAN KUALITAS DAN KELENGKAPAN DOKUMENTASI KEPERAWATAN. Jurnal IImiah STIKES Kendal Volume 9 No 3

10. Arif Puji Atmanto, Aggorowati dkk.2020. EFEKTIFITAS PEDOMAN PENDOKUMENTASIAN DIAGNOSA DAN INTERVENSI KEPERAWATAN BERBASIS ANDROID TERHADAP PENINGKATAN MUTU DOKUMENTASI KEPERAWATAN DI RUANG RAWAT INAP. Jurnal Keperawatan dan Kesehatan Masyarakat STIKES Cendekia Utama Kudus Vol. 9, No.1

11. Neneng Astuti, Yeni Yarnita, Eva Mayasari.2012.ANALISIS KELENGKAPAN PENDOKUMENTASIAN ASUHAN KEPERAWATAN PASIEN DI RUANG RAWAT INAP RUMAH SAKIT TAMPAN PEKANBARU. Jurnal Photon Vol. 1 No.1

12. Iyer, P.W.; Camp, N.H. (2004). Dokumentasi keperawatan suatu pendekatan proses keperawatan. Edisi 3. Jakarta: EGC 